\title{
Nuclear entropy, angular second moment, variance and texture correlation of thymus cortical and medullar lymphocytes: Grey level co-occurrence matrix analysis
}

\author{
IGOR PANTIC ${ }^{1}$, SENKA PANTIC ${ }^{2}$, JOVANA PAUNOVIC ${ }^{2}$ and MILAN PEROVIC ${ }^{3}$ \\ ${ }^{1}$ Laboratory for Cellular Physiology, Institute of Medical Physiology, School of Medicine, \\ University of Belgrade, Visegradska, 26/II, 11129 Belgrade, Serbia \\ ${ }^{2}$ Institute of Histology and Embryology, School of Medicine, \\ University of Belgrade, Visegradska, 26/II, 11129 Belgrade, Serbia \\ ${ }^{3}$ Hospital Center "Narodni Front", School of Medicine, \\ University of Belgrade, Kraljice Natalije, 62, 11000 Belgrade, Serbia
}

Manuscript received on April 3, 2012; accepted for publication on October 11, 2012

\begin{abstract}
Grey level co-occurrence matrix analysis (GLCM) is a well-known mathematical method for quantification of cell and tissue textural properties, such as homogeneity, complexity and level of disorder. Recently, it was demonstrated that this method is capable of evaluating fine structural changes in nuclear structure that otherwise are undetectable during standard microscopy analysis. In this article, we present the results indicating that entropy, angular second moment, variance, and texture correlation of lymphocyte nuclear structure determined by GLCM method are different in thymus cortex when compared to medulla. A total of 300 thymus lymphocyte nuclei from 10 one-month-old mice were analyzed: 150 nuclei from cortex and 150 nuclei from medullar regions of thymus. Nuclear GLCM analysis was carried out using National Institutes of Health ImageJ software. For each nucleus, entropy, angular second moment, variance and texture correlation were determined. Cortical lymphocytes had significantly higher chromatin angular second moment $(\mathrm{p}<$ $0.001)$ and texture correlation $(\mathrm{p}<0.05)$ compared to medullar lymphocytes. Nuclear GLCM entropy and variance of cortical lymphocytes were on the other hand significantly lower than in medullar lymphocytes (p $<0.001)$. These results suggest that GLCM as a method might have a certain potential in detecting discrete changes in nuclear structure associated with lymphocyte migration and maturation in thymus.
\end{abstract}

Key words: texture analysis, GLCM matrix, CD4, CD8, gene.

\section{INTRODUCTION}

During the past several decades, there have been numerous research efforts to design and implement a simple, accurate, and affordable computational biology method for quantification and evaluation of nuclear architecture. Many of the developed

Correspondence to: Igor Pantic

E-mail: igor.pantic@mfub.bg.ac.rs /

igorpantic@gmail.com techniques include image analysis of cell cultures and stained tissue micrographs, and they combine standard morphometric measurements with second and higher order statistical parameters. One of the recently applied techniques that include second order statistical texture analysis is the so-called grey level co-occurrence matrix method (GLCM). GLCM is a rapid mathematical method for assessing image structural properties, such as homogeneity, 
complexity and level of disorder. It was introduced in the work of Haralick et al. (1973), who have established a total of 14 parameters based on pixel pair grey level occurrences within a grey scale image. In time, GLCM was successfully applied in nuclear magnetic resonance imaging (Li et al. 2009), computed tomography (Huber et al. 2011) and other clinical research areas. In fundamental medical and biology research, Shamir et al. demonstrated that tissue GLCM entropy is an indicator of tissue age-related structural degradation (Shamir et al. 2009). Losa et al. suggested that in cell cultures, GLCM parameters of nuclear structure may be important for evaluation of chromatin structural changes during apoptosis (Losa and Castelli 2005).

Today, of all GLCM parameters, entropy, angular second moment (ASM), variance and texture correlation are perhaps most commonly used in experimental and clinical medicine (Shamir et al. 2009, Pantic and Pantic 2012, Pantic et al. 2012a, Losa and Castelli 2005, Li et al. 2009, Alvarenga et al. 2010). In recent research carried out by our laboratory, we have suggested that GLCM entropy and angular second moment can be successfully used to evaluate structural properties of a secondary lymphoid organ. In immunized guinea-pigs, entropy of spleen germinal centers was negatively correlated with humoral immune response, indicating that entropy may be a good predictor of structural deterioration and degradation that occurs in spleen germinal center tissue (Pantic and Pantic 2012). Also, in another study, we found that in germinal center light zones (where the process of B-lymphocyte selection takes place), entropy and angular second moment of lymphocyte nuclear structures are related to the nuclear size (Pantic et al. 2012a). These results suggested that nuclear GLCM parameters may be good indicators of structural changes that follow the shrinkage of nuclei during early stages of programmed cell death (apoptosis) in spleen white pulp.
Unlike secondary lymphoid organs, there are virtually no data regarding primary lymphoid organ nuclear GLCM properties. In this article, we present the results indicating that lymphocytes located in thymus cortex have significantly different nuclear entropy, ASM and correlation, when compared to the lymphocytes located in thymus medulla. These findings suggest that GLCM as a method might be capable of detecting fine structural changes in cell nuclei associated with migration and maturation of thymus lymphocytes.

\section{MATERIALS AND METHODS}

Thymus tissue was obtained from 10 male onemonth-old Swiss white albino outbred mice. All animals were previously bread and kept under same laboratory and environmental conditions (standard laboratory diet, ambient temperature of $22^{\circ} \mathrm{C}$, natural light cycle). The research followed the rules presented in the Guide for the Care and Use of Laboratory Animals, published by the U.S. National Institute of Health (NIH Publication No. 85 -23 , revised 1985). The principal investigator (IP) had an authorization from the Ethical Commission of the University of Belgrade, School of Medicine, and the Serbian Ministry of agriculture for the experimental work with the laboratory animals (Approval No. 323-07-03985/2012-05/1).

Thymus tissue was fixated in Carnoy solution, mounted on glass slides ( 5 micrometer thickness), and stained with hematoxylin/ eosin (H/E). An Olympus C-5060 Wide Zoom digital camera instrument with an oil immersion objective $(\times 1,000$ magnification $)$ of Olympus BX41 microscope (1 pixel equaled $0.048 \mu \mathrm{m}$ ) was used for micrograph acquisition similarly to our previous study (Pantic et al. 2012a). A total of 300 thymus lymphocyte nuclei (30 randomly selected non-overlapping lymphocyte nuclei from each animal) were analyzed: 150 from cortex (15 per animal) and 150 from medullar regions (15 per animal) of thymus (figure 1). 

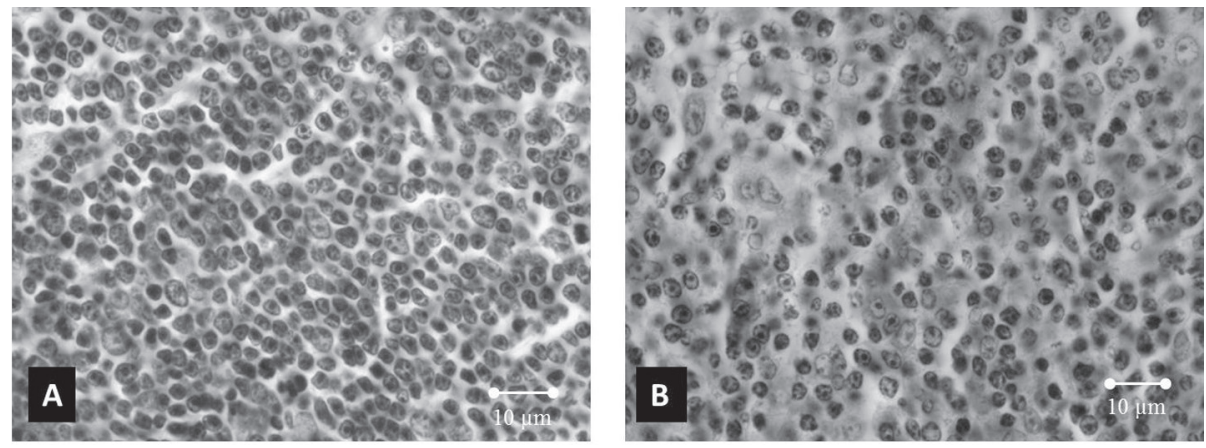

Figure 1 - Digital micrographs (1,000x magnification) of thymus cortex (A) and medulla (B).

Nuclear image acquisition was done after creating an automatic threshold of the nuclear boundaries in 8-bit format using National Institutes of Health ImageJ (version 1.44p) software. The following protocol was used for each nucleus. The digital micrographs of thymus cortex/medulla in tiff format were converted to 8-bit (ImageJ $>$ Type $>8$-bit). The converted 8-bit micrographs were then processed using the function Image $\mathrm{J}>$ Adjust $>$ Threshold. During the visualization of the nuclei in ImageJ software, two independent histology experts determined the values of the upper and lower threshold level settings, which in their opinion, provided the most accurate quality of the segmentation. Upper threshold level was set to 110 while lower threshold level was 0. Although this visual evaluation of automatic image processing is subjective in nature, we assume that it has not significantly influenced the final results, as the values of GLCM parameters depend much more on textural patterns of the interior of the nuclei, than on precision of nuclear boundary determination. The sample of non-overlapping lymphocyte nuclei was selected by "Wand tracing tool" (Mode: Legacy, Tolerance:0.0) and cropped (Image J $>$ Image $>$ Crop). After the cropping process, individual nuclei images were analyzed by GLCM method.

GLCM method was first introduced in 1973, by Haralick et al. who developed a method able to quantify spatial relationship between grey tones (pixel brightness values) in an image. This method uses "second order" statistics, which means that it estimates the relationship between groups of two resolution cells (pixels) separated by a defined distance d. GLCM analysis in our study was carried out by ImageJ and its texture analysis plugins developed by Julio E. Cabrera, and Toby C. Cornish.

Grey level co-occurrence matrix entropy, angular second moment, variance and correlation for each nucleus were calculated based on the following formulas:

$$
\begin{aligned}
& \text { Entropy }=-\sum_{i} \sum_{j} p(i, j) \log (p(i, j)) \\
& \text { Angular second moment }=\sum_{i} \sum_{j}\{p(i, j)\}^{2} \\
& \text { Variance }=\sum_{i} \sum_{j}(i-\mu)^{2} p(i, j) \\
& \text { Correlation }=\frac{\sum_{i} \sum_{j}(i j) p(i, j)-\mu_{x} \mu_{x}}{\sigma_{x} \sigma_{x}}
\end{aligned}
$$

where $i$ and $j$ are coordinates of the cooccurrence matrix, whereas $\sigma$ and $\mu$ represent means and standard deviations of $\mathrm{p}_{\mathrm{x}}$ and $\mathrm{p}_{\mathrm{y}}$ for a selected distance $d$ and angle $\theta$ (Haralick et al. 1973).

GLCM parameters were determined separately for direction angles $\theta$ equal to $0^{\circ}, 45^{\circ}, 90^{\circ}$ and $135^{\circ}$, as well as distances $\mathrm{d}=1, \mathrm{~d}=2$ and $\mathrm{d}=3$, after which the average values were calculated similarly to the work of Losa and Castelli (2005). This way, a total of 3,600 individual GLCM measurements were calculated. For details regarding the mathematical protocol of the study, the reader is referred to our 
previous articles on this subject (Pantic and Pantic 2012, Pantic et al. 2012a), the work of Haralick et al. (1973), as well as technical data of National Institutes of Health ImageJ software.

Statistical analysis was done using GraphPad Prism software (La Jolla, CA, USA) and SPSS statistical package (v. 10; SPSS Inc., Chicago, IL, USA). Student's t-test was used to determine possible statistically significant difference between cortical and medullar lymphocytes.

\section{RESULTS}

Average values of GLCM entropy, angular second moment and correlation for different GLCM distances $d$ are presented in table I. All parameters presented statistically significant difference.

TABLE I

Average values of chromatin entropy, angular second moment, variance and correlation for different GLCM distances (d).

\begin{tabular}{|c|c|c|c|c|}
\hline GLCM feature & & $\mathrm{d}=1$ & $\mathrm{~d}=2$ & $\mathrm{~d}=3$ \\
\hline \multirow{2}{*}{ Entropy } & Cortex & $6.389 \pm 0.253$ & $6.537 \pm 0.264$ & $6.611 \pm 0.270$ \\
\cline { 2 - 5 } & Medulla & $6.510 \pm 0.280 * * *$ & $6.675 \pm 0.294 * * *$ & $6.756 \pm 0.301 * * *$ \\
\hline \multirow{2}{*}{$\begin{array}{c}\text { Angular second } \\
\text { moment }\end{array}$} & Cortex & $0.0021 \pm 0.0006$ & $0.0018 \pm 0.0005$ & $0.0016 \pm 0.0005$ \\
\cline { 2 - 5 } Variance & Medulla & $0.0019 \pm 0.0007 * * *$ & $0.0016 \pm 0.0006^{* * *}$ & $0.0014 \pm 0.0006^{* * *}$ \\
\cline { 2 - 5 } & Cortex & $174.3 \pm 102.8$ & $170.8 \pm 98.1$ & $170.8 \pm 96.4$ \\
\hline \multirow{2}{*}{ Correlation } & Medulla & $216.4 \pm 108.5 * * *$ & $212.1 \pm 104.3 * * *$ & $211.4 \pm 102.9 * * *$ \\
\cline { 2 - 5 } & Cortex & $0.0065 \pm 0.0030$ & $0.0058 \pm 0.0025$ & $0.0048 \pm 0.0019$ \\
\hline
\end{tabular}

${ }^{*} p<0.05, * * p<0.01, * * * p<0.001$.

For distance $d=1$, mean entropy was $6.389 \pm$ 0.253 for cortical lymphocytes and $6.510 \pm 0.280$ for medullar lymphocytes. The difference between the two lymphocyte populations was statistically highly significant $(\mathrm{p}<0.001$, figure 2$)$. Average angular second moment for cortical lymphocytes was $0.0021 \pm 0.0006$, and it was significantly higher than the ASM of medullar lymphocytes $(0.0019 \pm$ $0.0007, \mathrm{p}<0.001$, figure 2). Mean GLCM variance in cortical and medullar lymphocytes were $174.3 \pm$ 102.8 and $216.4 \pm 108.5$, respectively $(\mathrm{p}<0.001)$. Mean texture correlation of cortical lymphocytes was significantly higher than correlation of medullar lymphocytes $(0.0065 \pm 0.0030$ versus $0.0055 \pm 0.0038, \mathrm{p}<0.05$, figure 2).

For distance $d=2$, mean entropy was $6.537 \pm$ 0.264 for cortical lymphocytes and $6.675 \pm 0.294$ for medullar lymphocytes. The entropy of medullar lymphocytes was significantly higher $(p<0.001$, figure 2). Similar results were found for textural variance $(\mathrm{p}<0.001 ; 170.8 \pm 98.1$ versus $212.1 \pm$ 104.3). Cortical lymphocyte population had higher $\operatorname{ASM}(0.0018 \pm 0.0005$ versus $0.0016 \pm 0.0006$, p $<0.001$, figure 2$)$ and texture correlation $(0.0058 \pm$ 0.0025 versus $0.0050 \pm 0.0033, \mathrm{p}<0.05$, figure 2).

For distance $d=3$, mean ASM was $0.0016 \pm$ 0.0005 for cortical lymphocytes and $0.0014 \pm 0.0006$ for medullar lymphocytes. The difference between the two lymphocyte populations was statistically highly significant $(\mathrm{p}<0.001$, figure 2$)$. Cortical lymphocyte population had lower entropy $(6.611 \pm$ 0.270 versus $6.756 \pm 0.301, p<0.001$, figure 2 ) and variance $(170.8 \pm 96.4$ versus $211.4 \pm 102.9)$ as well as higher texture correlation $(0.0048 \pm 0.0019$ versus $0.0043 \pm 0.0027, \mathrm{p}<0.05$, figure 2).

Of all determined parameters, entropy in both thymus regions showed the highest degree of homogeneity with inter and intra-individual 
a
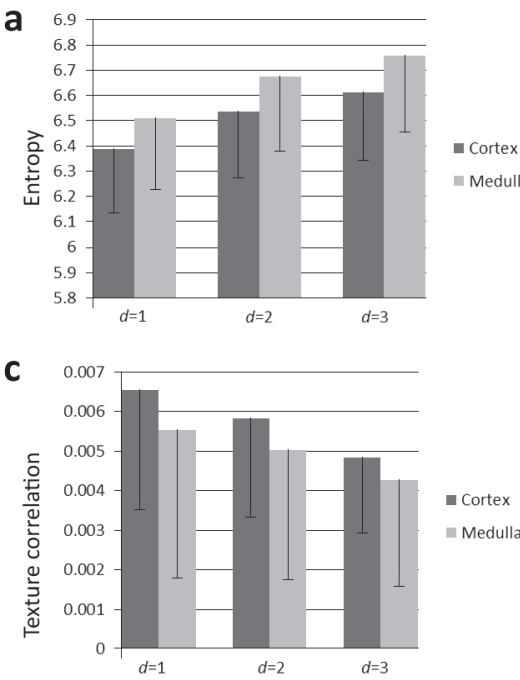

b

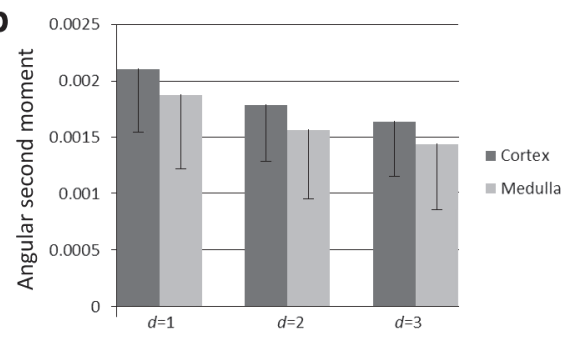

d

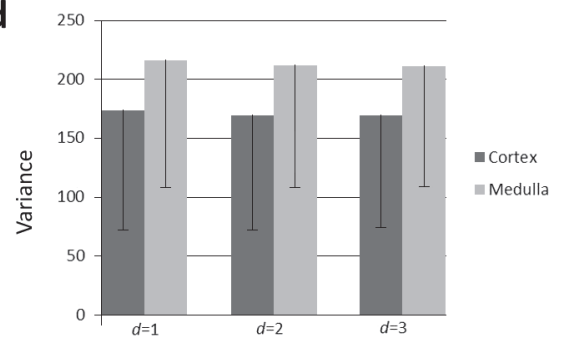

Figure 2 - GLCM entropy (a), angular second moment (b), correlation (c) and variance (d) of thymus cortical and medullar lymphocyte nuclei.

variability lower than $10 \%$. There was no significant difference in GLCM parameters between individual animals (ANOVA, $\mathrm{p}>0.05$ ).

For each GLCM parameter $a$ receiver operating characteristic (ROC) curve was constructed to illustrate the performance of the parameter as a binary classifier of lymphocyte nuclei in terms of their location in thymus. As presented in figure 3, the areas under the ROC curves were 0.652 for entropy, 0.649 for angular second moment, 0.626 for correlation and 0.637 for variance.

\section{DISCUSSION}

The results of our study suggest that lymphocytes of thymus medulla might have higher nuclear GLCM entropy and variance than lymphocytes in thymus cortex. Angular second moment and texture correlation are on the other hand lower in medullar lymphocytes. In biology research, these GLCM parameters are generally seen as indicators of cell/tissue structural complexity and heterogeneity. High entropy and variance usually implies elevated level of disorder and disorganization, whereas angular second moment is a measure of homogeneity (Shamir et al. 2009,
Haralick et al. 1973). Texture correlation is a measure of grey level linear dependencies in a micrograph (Haralick et al. 1973) and can have values from 0 (uncorrelated micrograph) to +1 and -1 (perfectly correlated). GLCM parameters are today commonly used for quantification of cell/ tissue texture, and for detection of fine cell/tissue structural changes that are otherwise undetectable during standard microscopy analysis.

Thymus is a primary lymphoid organ with various biological functions regarding immune system development and its ability to respond to infections. Cortex and medulla are two major thymus histological compartments. Both compartments consist primarily of T-lymphocytes (T-cells), cells which are essential for adaptive immune responses. One of the main events that take place in thymus environment is selection and maturation of T-cells. In cortex, these cells undergo the so-called "T-cell receptor gene rearrangement", a process involving random joining of gene segments in nucleus in order to form a genetic sequence responsible for creation of cell surface T-cell receptor (TCR), which is an essential property of a functional T-lymphocyte antigen recognition ability (Sleckman 2005, Nitta et 

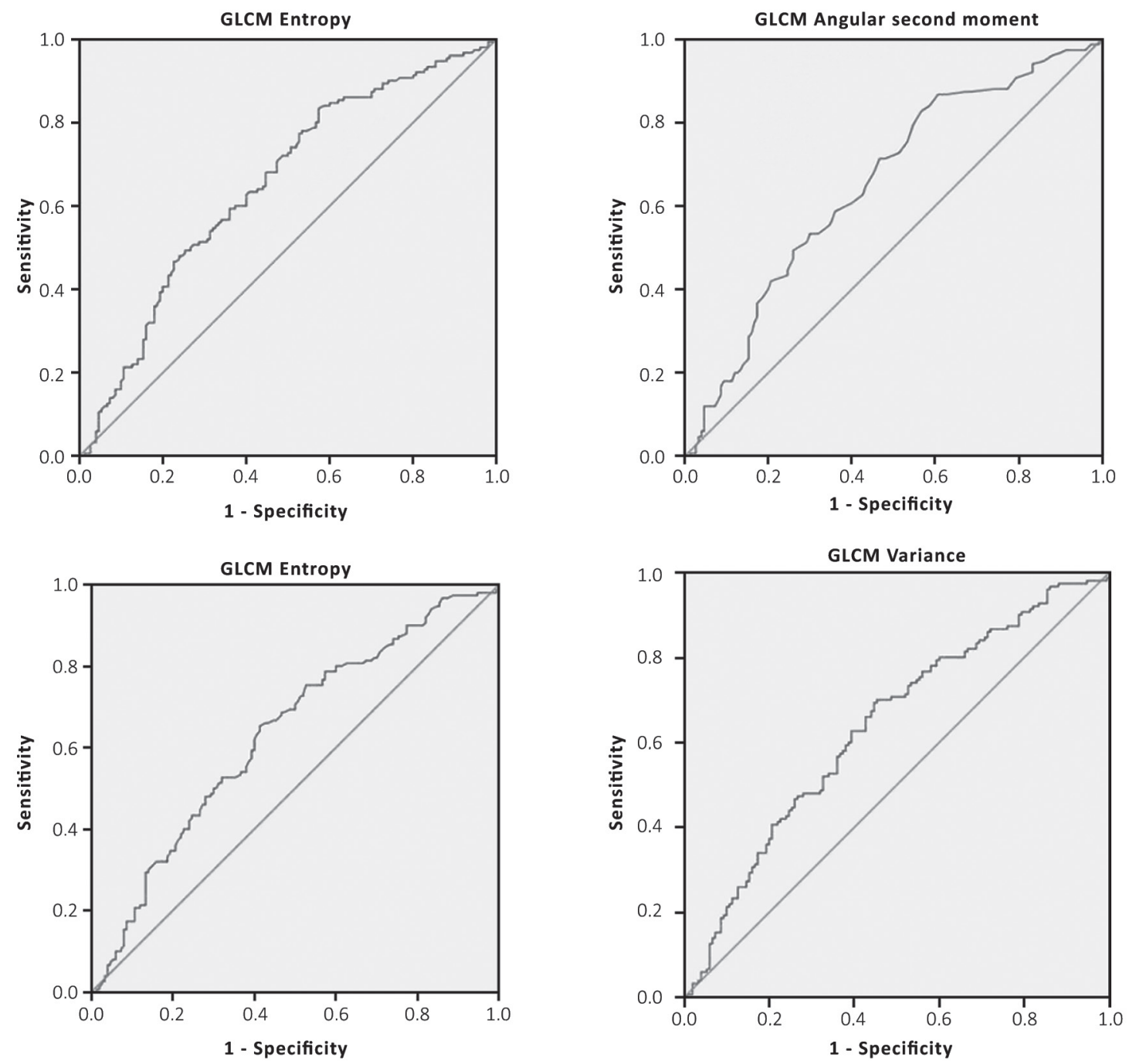

Figure 3 - Receiver operating characteristic (ROC) curves for GLCM parameters.

al. 2008, Krangel 2009, Seitan et al. 2011). After this TCR gene rearrangement, the T-cell expresses two surface TCR co-receptor CD molecules: CD4 and CD8 (double positive CD4+CD8+ immature T-cell).

Another process that takes place in thymus cortex is positive selection of immature T-cells (Teng et al. 2011, Takahama et al. 2010, Klein et al. 2009, Gommeaux et al. 2009). Lymphocytes that have T-cell receptor capable of binding to a major histocompatibility complex (MHC) molecule, receive pro-survival signal. It is thought that during positive selection approximately $90 \%$ of immature T-cells (double positive $\mathrm{CD} 4+\mathrm{CD} 8+$ ) fail to receive this signal as their TCR is unable to interact with MHC molecule (Clarke et al. 2009). As a result, these cells go through programmed cell death (apoptosis). The remaining, surviving T-cells become either CD4+CD8- or CD4-CD8+ (single positive) through the process of downregulation and upregulation. This lineage commitment is followed by migration of single positive T-cells to thymus medulla (Teng et al. 2011, Kurobe et al. 2006, Choi et al. 2008).

In thymus medulla, the single positive T-cells that show affinity to self-antigens presented on MHC molecules receive pro-apoptotic signal (Le 
Borgne et al. 2009, Qiu et al. 2010, Atibalentja et al. 2009, McCaughtry et al. 2008). This elimination of auto-reactive T-cells is called negative selection, and its main purpose is to prevent the development of autoimmunity. Although negative selection can also occur in double positive T-cells in cortex, it is much more pronounced and efficient in medulla.

Therefore, cortical and medullar lymphocytes, although all being T-cells, have some major differences in their functional and maturational status. First, these two populations have different expression of TCR co-receptor CD molecules: cortical lymphocytes are predominantly double negative (CD4-CD8-) or double positive $(\mathrm{CD} 4+\mathrm{CD} 8+)$, while medullar, more mature lymphocytes are mostly single positive (CD4+CD8or $\mathrm{CD} 4-\mathrm{CD} 8+$ ). Second, the microenvironment of thymus cortex is substantially different than in medulla; this refers to different interleukin levels, presence or absence of certain growth factors, as well as differences in epithelial reticular cell functions (Nitta et al. 2008, Benz et al. 2004, Ma et al. 2013). All these factors can have an impact on nuclear structural organization of the two lymphocyte populations.

Our results indicate that GLCM as a method may be capable of detecting discrete nuclear structural changes that are associated with thymus lymphocyte migration and maturation. This is in accordance with the study of Losa and Castelli (2005) who suggested that some GLCM parameters (i.e. textural correlation) may be very efficient in identifying chromatin organizational changes in cell cultures, in some cases with greater sensitivity than conventional molecular biology methods such as TdT-mediated dUTP nick end labeling assay, FACScan Sub G0/G1 peak, or Annexin-V labelling. In our study, of analyzed GLCM parameters, changes in entropy, variance and angular second moment were more pronounced than in correlation. In our study, in addition to the standard statistical difference tests, the ability of the GLCM parameters to discriminate the two lymphocyte populations was tested by ROC analysis. In clinical sciences, ROC analysis is essential for evaluating potential value of the studied diagnostic test. ROC curve is constructed based on the fraction of true positives out of the positives (sensitivity) and the fraction of false positives out of the negatives (1-specificity), taking into account different thresholds. In our work, in SPSS software "state variable"=1 was assigned to the cortical lymphocytes, while "state variable" $=0$ was assigned to the medullar lymphocytes. Therefore, cortical location would be equivalent to "positive" diagnosis in a clinical diagnostic test.

Potential discriminatory performance of the test is evaluated by analyzing the area under the ROC curve. A test with no diagnostic value would have the area under the ROC curve approximately higher than 0.5 and lower than 0.6. Area between 0.6 and 0.7 indicates "poor" performance, area between 0.7 and 0.8 "fair" performance, and area between 0.8 and 0.9 "good" performance (Zweig and Campbell 1993, Sandelowsky et al. 2011). Tests that belong to the category "excellent" usually have the ROC areas higher than 0.9.

In this study, all four tested GLCM parameters had ROC areas between 0.6 and 0.7 , with entropy having the highest accuracy and correlation the lowest. Although these values show relatively low discriminatory performance of GLCM parameters, it should be noted that at present there is no known image analysis method that would represent a gold standard for nuclear structure classification in thymus. Also, we cannot exclude the possibility that in some future study, a scoring system combining various GLCM parameters could be designed and would have much higher performance than individual GLCM parameters taken separately. Alternatively, one could combine GLCM method with other known image complexity analysis techniques, such as fractal analysis, particularly having in mind that some computational biology 
programs (i.e. ImageJ) can be easily upgraded to apply both techniques on same digital micrographs (Pantic et al. 2012b).

The presented findings regarding entropy and angular second moment are also in accordance with the results of our previous study concerning GLCM analysis of B-lymphocytes (B-cells) in spleen germinal center (Pantic et al. 2012a). We suggest that nuclear structural entropy and ASM of spleen germinal center light zone B-cell nuclei are correlated with nuclear structural reorganization during apoptosis. This reorganization may have included chromatin condensation, marginalization and fluctuations in euchromatin / heterochromatin ratio. The chromatin changes that occur during lymphocyte maturation in thymus (and migration from cortex to medulla) are probably more discrete than the ones taking place in germinal center, which makes GLCM as a method potentially even more sensitive than previously thought.

Our study had several potential limitations. First, all 300 analyzed lymphocyte nuclei originated from thymus tissues of one-month-old mice. It is well known that with age, thymus as a primary lymphoid organ begins to atrophy, followed by its decreased function (Calder et al. 2011, Gruver et al. 2007). It remains unclear whether GLCM method would detect the same differences between cortical and medullar lymphocyte chromatin in older tissues. Perhaps, in the future, it would be of interest to conduct a similar, but larger study which would investigate possible effects of aging on T-cell chromatin GLCM parameters. Second, if we consider the total number of T-cells that are present in thymus at a given time, the sample of 300 nuclei is somewhat limited. Nevertheless, we should have in mind that GLCM as a mathematical and computational biology method is relatively exact and when combined with NIH ImageJ software, it significantly lowers possible measurement variations that would otherwise be the result of subjective interpretation, researcher bias, or small sample size.
In conclusion, our findings suggest that grey level co-occurrence matrix entropy, angular second moment, variance and correlation might be useful in detection of discrete structural changes of lymphocyte nuclei in thymus. Although discriminatory performance of the calculated GLCM parameters is relatively poor, we assume that in the future, a more sensitive scoring system based on a combination of individual GLCM features could be designed. Along with results of other studies, it would represent a basis for further research regarding applicability of GLCM method in medical and biological sciences.

\section{ACKNOWLEDGMENTS}

The authors are grateful to The Ministry of Education and Science, Republic of Serbia, Research Projects oi-175059 and iii-41027, as well as the staff at The Institute of Physiology Dragisa Nikitovic and Dragana Pavlovic for their help in obtaining the laboratory animals.

The authors report no conflict of interests regarding this manuscript.

\section{RESUMO}

Análise da matriz de co-ocorrência de níveis de cinza (GLCM) é um método matemático bem conhecido para a quantificação das propriedades estruturais das células e tecidos, incluindo homogeneidade, complexidade e nível de desordem. Recentemente foi demonstrado que esse método é capaz de avaliar as mudanças estruturais finas do núcleo que, de outra forma não são detectáveis pela análise microscópica habitual. Nesse artigo, apresentamos resultados indicando que a entropia, segundo momento angular, variância, e correlação de textura da estrutura nuclear de linfócitos, determinada pelo método de GLCM, diferem na córtex do timo em comparação a medula. Um total de 300 núcleos de linfócitos do timo de 10 camundongos de um mês de idade foram analisados: 150 núcleos da córtex e 150 núcleos da medula do timo. Análise de GLCM nuclear foi realizada usando o software ImageJ do National Institutes 
of Health (NIH). Para cada núcleo, entropia, segundo momento angular, variância e correlação de textura foram determinadas. Linfócitos corticais continham significativamente maiores os parâmetros segundo momento angular da cromatina $(\mathrm{p}<0.001)$ e correlação de textura $(\mathrm{p}<0.05)$ comparados a linfócitos medulares. A entropia GLCM nuclear e variância de linfócitos corticais eram por outro lado significativamente menores que nos linfócitos medulares ( $p<0.001)$. Esses resultados sugerem que GLCM como método tenha um potencial de detector mudanças discretas na estrutura nuclear associadas a migração e maturação de linfócitos no timo.

Palavras-chave: análise de textura, matriz GLCM, CD4, CD8, gene.

\section{REFERENCES}

alvarenga AV, Teixeira CA, Ruano MG and Pereira WC. 2010. Influence of temperature variations on the entropy and correlation of the Grey-Level Co-occurrence Matrix from B-Mode images. Ultrasonics 50: 290-293.

ATIBALENTJA DF, BYERSDORFER CA AND UNANUE ER. 2009. Thymus-blood protein interactions are highly effective in negative selection and regulatory $\mathrm{T}$ cell induction. $\mathrm{J}$ Immunol 183: 7909-7918.

BENZ C, HeINZEL K AND BLEUL CC. 2004. Homing of immature thymocytes to the subcapsular microenvironment within the thymus is not an absolute requirement for $\mathrm{T}$ cell development. Eur J Immunol 34: 3652-3563.

Calder AE, Hince MN, Dudakov JA, Chidgey AP and BOYD RL. 2011. Thymic involution: where endocrinology meets immunology. Neuroimmunomodulation 18: 281-289.

Chol YI, Duke-Cohan JS, Ahmed WB, Handley MA, ManN F, EPSTEIn JA, Clayton LK and ReINHeRz EL. 2008. PlexinD1 glycoprotein controls migration of positively selected thymocytes into the medulla. Immunity 29: 888-898.

Clarke RL, Thiemann S, Refaeli Y, Werlen G AND Potter TA. 2009. A new function for LAT and CD8 during CD8mediated apoptosis that is independent of TCR signal transduction. Eur J Immunol 39: 1619-1631.

Gommeaux J, Grégoire C, Nguessan P, Richelme M, Malissen M, Guerder S, Malissen B and CARrier A. 2009. Thymus-specific serine protease regulates positive selection of a subset of CD4+ thymocytes. Eur J Immunol 39: 956-964.

GRUVER AL, HUDSON LL AND SEMPOWSKI GD. 2007. Immunosenescence of ageing. J Pathol 211: 144-156.

HARALICK RM, SHANMUGam K AND DinSTEIN I. 1973. Textural Features for Image Classification. IEEE Transactions on Systems Man Cybernetics 3: 610-621.
Huber MB, Nagarajan MB, Leinsinger G, Eibel R, Ray LA AND WISMÜLLER A. 2011. Performance of topological texture features to classify fibrotic interstitial lung disease patterns. Med Phys 38: 2035-2044

IMAGE J. 2011. National Institutes of Health (NIH). http:// rsbweb.nih.gov/ij Accessed 26 December 2011.

KLEIN L, Hinterberger M, Wirnsberger G AND KyeWSKI B. 2009. Antigen presentation in the thymus for positive selection and central tolerance induction. Nat Rev Immunol 9: 833-844.

KRANGEL MS. 2009. Mechanics of T cell receptor gene rearrangement. Curr Opin Immunol 21: 133-139.

KUROBE H ET AL. 2006. CCR7-dependent cortex-to-medulla migration of positively selected thymocytes is essential for establishing central tolerance. Immunity 24: 165-177.

Le Borgne M, Ladi E, Dzhagalov i, Herzmark P, Liao YF, CHAKRABORTY AK AND ROBEY EA. 2009. The impact of negative selection on thymocyte migration in the medulla. Nat Immunol 10: 823-830.

Li X, Pai A, Blumenkrantz G, Carballido-Gamio J, LinK T, Ma B, Ries M AND MaJUmdar S. 2009. Spatial distribution and relationship of T1rho and $\mathrm{T} 2$ relaxation times in knee cartilage with osteoarthritis. Magn Reson Med 61: 1310-1318.

LOSA GA AND CASTELLI C. 2005. Nuclear patterns of human breast cancer cells during apoptosis: characterisation by fractal dimension and co-occurrence matrix statistics. Cell Tissue Res 322: 257-267.

MA D, WeI Y AND LIU F. 2013. Regulatory mechanisms of thymus and T cell development. Dev Comp Immunol 39: 91-102.

MCCAUGHTRY TM, BALDWIN TA, WILKEN MS AND HOGQUIST KA. 2008. Clonal deletion of thymocytes can occur in the cortex with no involvement of the medulla. J Exp Med 205: 2575-2584.

Nitta T, Murata S, Ueno T, Tanaka K and Takahama Y. 2008. Thymic microenvironments for T-cell repertoire formation. Adv Immunol 99: 59-94.

Pantic I, HarhajI-Trajkovic L, Pantovic A, Milosevic NT AND TRAJKovic V. 2012b. Changes in fractal dimension and lacunarity as early markers of UV-induced apoptosis. J Theor Biol 303: 87-92.

PANTIC I AND PANTIC S. 2012. Germinal center texture entropy as possible indicator of humoral immune response: immunophysiology viewpoint. Mol Imaging Biol 14: 534-540.

Pantic I, Pantic S and Basta-Jovanovic G. 2012a. Grey level co-occurrence matrix (GLCM) texture analysis of germinal center light zone lymphocyte nuclei: physiology viewpoint with focus on apoptosis. Microsc Microanal 18: 470-475.

Qiu Q, Ravens I, Seth S, Rathinasamy A, Maier MK, DAVAlos-Misslitz A, Forster R AND BERnhardt G. 2010. CD155 is involved in negative selection and is required to retain terminally maturing $\mathrm{CD} 8 \mathrm{~T}$ cells in thymus. J Immunol 184: 1681-1689. 
SANDELOWSKY H, STÄLLBERG B, NAGER A AND HASSELSTRÖM J. 2011. The prevalence of undiagnosed chronic obstructive pulmonary disease in a primary care population with respiratory tract infections - a case finding study. BMC Fam Pract 12, 122 p.

SEITAN VC ET AL. 2011. A role for cohesin in T-cell-receptor rearrangement and thymocyte differentiation. Nature 476: 467-471.

SHAMIR L, Wolkow CA AND GOLDBERG IG. 2009. Quantitative measurement of aging using image texture entropy. Bioinformatics 25: 3060-3063.

SLECKMAN BP. 2005. Lymphocyte antigen receptor gene assembly: multiple layers of regulation. Immunol Res 32: $253-258$.
Takahama Y, NitTa T, Mat Ripen A, NitTa S, Murata S AND TANAKA K. 2010. Role of thymic cortex-specific self-peptides in positive selection of $\mathrm{T}$ cells. Semin Immunol 22: 287-293.

TENG F ET AL. 2011. The molecular signature underlying the thymic migration and maturation of TCR $\alpha \beta+\mathrm{CD} 4+\mathrm{CD} 8$ thymocytes. PLoS One 6: e25567.

ZWEIG MH AND CAMPBELL G. 1993. Receiver-operating characteristic (ROC) plots: a fundamental evaluation tool in clinical medicine. Clin Chem 39: 561-577. 